\title{
The Impact of Unfair Treatment on Depressive Mood: The Moderating Role of Self-Esteem Level and Self-Esteem Instability
}

\author{
Laurenz L. Meier \\ Norbert K. Semmer \\ Jörg Hupfeld \\ University of Bern, Switzerland
}

This research examines the moderating roles of self-esteem level and self-esteem instability in the relationship between perceived unfair treatment and depressive mood. Based on the assumption that unfairness is a threat to one's social standing and self-esteem, the authors proposed that individuals with highly fragile self-esteem (i.e., the combination of unstable and high self-esteem) react more strongly when experiencing unfair treatment. This hypothesis was tested in a realworld setting using cross-sectional and diary data of 101 employees. As expected, unfair treatment was related to depressive mood among individuals with unstable high self-esteem but not among individuals with stable high self-esteem. This pattern of results held for both cross-sectional and diary data. In contrast, unfairness was not related to depressive mood among individuals with unstable low self-esteem.

Keywords: self-esteem; self-esteem instability; fairness; depressive mood

$\mathrm{R}$ esearch suggests that people are highly concerned about how fairly they are treated by others and that they react with impaired well-being to perceived unfairness (Folger \& Cropanzano, 1998). However, individuals differ in the degree to which they are reactive to unfair events (De Cremer, 2002a). This study focuses on individual differences by examining the moderating effects of self-esteem level and instability.

Unfair treatment can be regarded as a stressor. Stressors, both in terms of chronic conditions and in terms of negative daily events, affect psychological adjustment on a chronic level as well as on a daily level. For example, enduring stressors like the experience of workplace bullying and discrimination are related to anxiety and depression (e.g., Niedhammer, David, \& Degioanni, 2006; Schulz et al. 2006), and daily hassles are related to negative affect, low self-esteem, and depression on a daily level (e.g., Bolger, DeLongis, Kessler, \& Schilling, 1989; Nezlek \& Plesko, 2001, 2003; ZeiglerHill \& Showers, 2007). Chronic stressors and negative events vary in the degree of their severity. Events involving interpersonal rejection may be especially aversive because they undermine the fundamental need to belong to significant groups and to maintain good interpersonal relationships (Baumeister \& Leary, 1995). Previous research has shown that rejection is likely to compromise people's well-being (see Leary, 2001; Williams, 2007). Interpersonal rejection can take many forms and occurs in different social contexts, such as rejection by a romantic partner, bullying at school, exclusion from a sport club, or unfair treatment at the workplace.

Unfair treatment at the workplace can have different faces. Generally, researchers have identified three types of (un)fairness (see Colquitt, Greenberg, \& ZapataPhelan, 2005): first, fairness of outcomes (distributive fairness); second, fairness of procedures used for allocation decisions (procedural fairness); and third, fairness of interpersonal treatment during procedures

Authors' Note: Laurenz L. Meier and Norbert K. Semmer are affiliated with the Swiss Centre for Affective Sciences. We thank Ulrich Orth, Sven Gross, Fabienne T. Amstad, Martial Berset, Viviane Gisler, and Colm O'Mahony for their helpful comments on an earlier version of this article and Markus Hausammann, Christian Rohr, and David Schönenberger for their help during data collection. Correspondence concerning this article should be addressed to Laurenz L. Meier, Department of Psychology, University of Bern, Muesmattstrasse 45, CH-3000 Bern 9, Switzerland; e-mail: laurenz.meier@psy.unibe.ch.

PSPB, Vol. 35 No. 5, May 2009 643-655

DOI: $10.1177 / 0146167208331337$

(C) 2009 by the Society for Personality and Social Psychology, Inc. 
(interactional fairness). Early theories argued that people care about fair treatment (e.g., fair procedures) because of instrumental concerns of acquiring control over outcomes (Thibaut \& Walker, 1975), whereas later theories emphasized relational concerns (Lind \& Tyler, 1988; Tyler \& Lind, 1992). According to the groupvalue model of fairness (Lind \& Tyler, 1988), people care about fairness because fair behavior symbolizes that they are valued and respected members of a group, providing them with a high level of perceived inclusion in the group. Most of the research that supported the group-value model focused on procedural and interactional fairness. However, De Cremer (2002b) recently showed that distributional fairness also is perceived as self-relevant and informative about one's social standing. To summarize, unfair treatment may be generally perceived as a threat to social inclusion and likely affects people's well-being (Lind \& Tyler, 1988).

However, research suggests that not everybody reacts to unfairness to the same degree. Given that threat to social inclusion is a key characteristic of unfairness, people that have a disposition to be concerned about inclusion and, therefore, are highly attentive to indicators of exclusion should react stronger to unfairness than do people who have a secure feeling of inclusion. One important trait related to the feeling of inclusion is self-esteem. According to sociometer theory (Leary, Tambor, Terdal, \& Downs, 1995), the self-esteem system monitors the social environment for cues that indicate relational devaluation (e.g., disrespect, dislike, and rejection) and informs the individual by lowered selfesteem when such cues are detected. Hence, self-esteem mirrors the individual's relational value for inclusion in social relationships. In line with this, several studies have shown that people with low self-esteem feel less accepted by other people and more excluded from significant groups (e.g., Leary et al., 1995) and that they have greater concern about how they are evaluated by others (Heatherton \& Polivy, 1991). Furthermore, they are more reactive to signs of other's approval (e.g., Nezlek, Kowalski, Leary, Blevins, \& Holgate, 1997). Thus, people with low self-esteem should be particularly reactive to behavior that symbolizes relational devaluation like unfair behavior. To summarize, self-esteem level is supposed to moderate the impact of unfair treatment by others on one's well-being.

\section{UNFAIRNESS AND SELF-ESTEEM LEVEL}

In accordance with the reasoning outlined above, De Cremer, van Knippenberg, van Dijke, and Bos (2004) found unfair treatment by supervisors (i.e., interactional unfairness) to be negatively related to affective organizational commitment among civil servants with low self-esteem but not among those with high selfesteem. It should be noted that other authors reported contradicting findings. For example, Brockner et al. (1998) found that voice (i.e., procedural fairness) is of greater importance for people with high than with low self-esteem. However, Brockner et al. manipulated procedural fairness, whereas the other study focused on interactional fairness. Voice provides people with the opportunity to control events, which should be beneficial only for individuals with high self-efficacy beliefs, a construct conceptually related to high self-esteem (Judge, Erez, Bono, \& Thoresen, 2002). Thus, these findings are better explained in the framework of instrumental gains of fairness than in the framework of relational concerns (see De Cremer et al., 2004, for a similar reasoning). In contrast, De Cremer et al. (2004) focused on interactional fairness, which communicates important information about the social standing of the person. Therefore, it may be concluded that high self-esteem protects against the threat of social exclusion triggered by unfair treatment.

A similar point can be made from research on perceived discrimination (for an in-depth comparison of how fairness concepts are related to discrimination, see Stone-Romero \& Stone, 2005). In general, reports of discrimination are related to impaired mental health in cross-sectional (e.g., Fischer \& Bolton Holz, 2007; Moradi \& Subich, 2004) as well as in longitudinal studies (e.g., Schulz et al., 2006). However, of special interest in this context is that perceived discrimination is more strongly related to well-being among people with low self-esteem than with high self-esteem (Corning, 2002; Moradi \& Subich, 2004; however, see Fischer \& Shaw, 1999, for an opposite finding). This is in line with the above notion that low self-esteem individuals are more reactive to signs of other's approval and respect than are people with high self-esteem. In summary, previous research on unfair treatment and discrimination suggests that high self-esteem is a resilience factor for discrimination and unfair treatment.

\section{UNFAIRNESS AND SELF-ESTEEM INSTABILITY}

Whereas high self-esteem is likely to be a resilience factor, focusing exclusively on the level of self-esteem may be misleading. Kernis and colleagues (for an overview, see Kernis, 2005) showed that substantial short-term fluctuations of one's self-worth (i.e., selfesteem instability) is a vulnerability factor. People with unstable self-esteem are highly responsive to events that are potentially relevant to their self-worth, and they show a bias towards interpreting them as relevant for 
their self-esteem. Furthermore, they link their immediate feelings of self-worth to these events to a stronger degree and are more likely to focus on events that pertain to social exclusion (Greenier et al., 1999). To the extent that self-esteem mirrors perceived relational value (see Leary et al., 1995), people with unstable selfesteem (i.e., strong fluctuations) are not secure about their social standing and relational value. According to Leary (2004), this instability reflects a general hypersensitivity of the sociometer and, therefore, an overreaction to events that are relevant to one's social value and standing. Because unfair treatment is strongly tied to the perception of one's social standing, individuals with unstable self-esteem should be particularly reactive to unfair behavior. Empirical corroborations of this assumption are scarce. As yet, only one study has tested the moderating effect of self-esteem instability on the impact of perceived fairness: De Cremer and Sedikides (2005) showed that people with high self-uncertainty (unstable self-esteem, high self-doubts, and low selfconcept clarity) were more reactive to variations in procedural fairness. For example, affect was related to procedural fairness (i.e., accuracy of a procedure) only among participants with unstable self-esteem but not among those with stable self-esteem (De Cremer \& Sedikides, 2005, Experiment 2). As proposed earlier, these results indicate that people with unstable selfesteem react more strongly to unfair treatment than do people with stable self-esteem. However, De Cremer and Sedikides focused solely on instability without considering self-esteem level. Yet previous research has shown that self-esteem instability yields stronger (and less ambiguous) effects among individuals with high self-esteem as compared to those with low self-esteem (see Kernis \& Waschull, 1995).

\section{UNFAIRNESS, SELF-ESTEEM LEVEL, AND SELF-ESTEEM INSTABILITY}

Individuals with unstable high self-esteem are thought to have positive self-feelings that are fragile and that need continual validation. Negative self-relevant events are highly threatening for these people and evoke various self-protective efforts. For example, unstable high selfesteem has been linked to greater defensiveness (Kernis, Greenier, Herlocker, Whisenhunt, \& Abend, 1997) and a heightened propensity for hostility (Kernis, Grannemann, \& Barclay, 1989). Because people with unstable high selfesteem are especially vulnerable to threats, they should react particularly strongly to unfair treatment.

For individuals with low self-esteem, the role of instability is less clear. Paradise and Kernis (2002) reported that unstable as compared to stable low self-esteem is associated with personal growth and better psychological functioning in terms of relationships with others. In other studies, people with unstable low self-esteem had a comparably higher risk of subsequent depression (Kernis et al., 1998). Overall, findings are somewhat mixed among individuals with low self-esteem. Findings concerning the main effects of instability, therefore, should not be generalized to individuals with low and high self-esteem without caution. Without further evidence, it seems most reasonable to expect that both unstable and stable low self-esteem individuals care about their social standing and, hence, are especially attentive to cues of social inclusion (Leary et al., 1995). Unfair treatment, therefore, should be related to psychological adjustment among individuals with low self-esteem regardless of its stability.

\section{THIS STUDY}

To summarize, we suggest that unfair treatment is particularly relevant for individuals who are uncertain about their social standing. Individuals differ with regard to the concern about their social standing depending on both level and instability of their self-esteem. Previous research on fairness has focused solely on the moderating role of either self-esteem level or self-esteem instability with regard to different outcomes-but not on both. Furthermore, field studies are rare and even nonexistent with regard to the moderating role of self-esteem instability. This study extends previous research in two ways: by linking both self-esteem level and self-esteem instability to the impact of unfair treatment and by investigating this link in a real-world setting.

As discussed above, we hypothesize that unfair treatment is related to psychological adjustment to the same degree among people with unstable and stable low self-esteem. In contrast, we hypothesize that instability of self-esteem plays a crucial role for reactions among people with high self-esteem (Kernis, 2005). Individuals with unstable high self-esteem are highly insecure about their social standing, a characteristic that does not apply to those individuals with high stable self-esteem. Thus, the association between unfair treatment and psychological adjustment should be stronger for individuals with unstable high self-esteem than for those with stable high self-esteem. We, therefore, propose a three-way interaction between fairness, self-esteem level, and selfesteem instability. We expect self-esteem instability to moderate the relationship between fairness and wellbeing only among individuals with high self-esteem and not among those with low self-esteem.

In this study, we examined depressive mood as the outcome variable. Several authors have emphasized the 
importance of measuring people's affective reactions to perceived unfairness (e.g., Weiss, Suckow, \& Cropanzano, 1999). Previous research has clearly indicated that perception of unfairness is related to negative emotions and moods (e.g., Mikula, Scherer, \& Athenstaedt, 1998). Experimental and correlational studies investigating this association have frequently used rather broad measures of negative affect (for an overview, see CohenCharash \& Byrne, in press), although some researchers claim that it is important to focus on discrete affect (e.g., Weiss et al., 1999). Whereas most previous research examined effects on negative affect, the aforementioned studies that found moderating effects of self-esteem level (De Cremer et al., 2004) and instability (De Cremer \& Sedikides, 2005) focused on positive affect and behavior. However, we propose that the moderating effect of self-esteem level and instability should also be found for negative affect, more precisely for depressive mood. Previous research has shown that rejection by others is related to feelings of sadness and depression (Leary, 1990; Leary et al., 1995). Sadness and depression may be caused by a variety of negative events, but failing to feel accepted and included is especially pertinent (Baumeister \& Leary, 1995). In line with this assumption, depression is negatively related to the degree to which one feels accepted by others (Tambor $\&$ Leary, 1993, as cited in Baumeister \& Leary, 1995) and prospective studies have shown that rejection (e.g., Nolan, Flynn, \& Garber, 2003) and perceived unfairness in the workplace (Ylipaavalniemi et al., 2005) predict the development of depression.

We tested our hypothesis under two different time perspectives, namely on a diary and on a chronic level. The chronic level can be understood as an aggregation of diary-level events. In other words, experiencing chronic low interactional justice means that a person frequently feels unfairly treated by his or her supervisor. Thus, if individuals with unstable high self-esteem react with depressive mood to single events (diary level), it is likely that for these individuals chronic unfairness is linked to chronic depressive mood. Therefore, chronic unfair treatment (i.e., low interactional fairness) is expected to be related to the concurrent level of work-related depressive mood (cross-sectional study design) and unfair treatment on a working day is hypothesized to be associated with depressive mood on the same day (diary study design). Taken together, unfairness in the workplace is supposed to exert a negative impact on depressive mood in the short run as well as over a more prolonged period of time. In both cases, we expect that not only people with low selfesteem but also people with unstable high self-esteembut not those with stable high self-esteem-will react strongly to unfairness.

\section{METHOD}

\section{Sample and Data Collection}

The sample consisted of 101 employees (60\% males) from a Swiss government department. The age of the participants ranged from 17 to 64 years, with an average age of 41.9 years $(S D=11.4)$. Participants were working in various jobs, and their level of education was above average $(75 \%$ had a university or college degree). Organizational tenure ranged from 0.5 to 32.0 years; average tenure was 8.1 years $(S D=7.2)$. Most of the participants $(74 \%)$ were employed full-time, and the average level of employment, expressed as percentage of a full-time equivalent, was $95 \%$.

Participants completed a paper-and-pencil questionnaire that assessed characteristics of the workplace, wellbeing, and personality. The next day, they received a link for the diary online survey via e-mail. This second part of data collection had previously been announced. Participants logged into the Web site using a personal password and received information on the purpose and procedure of this daily online assessment. They proceeded to fill in questionnaires measuring the study variables that are labeled below as daily-level variables. Whereas most diary studies administer the daily survey at the end of the working day (e.g., Sonnentag \& Zijlstra, 2006), we had to deliver it before lunch break. We knew from pilot interviews that many employees of this department work out of the office in the afternoon and would not be able to complete the online survey. Because some employees regularly worked out of office for full days, sampling was conducted over 2 weeks to assure that sufficient daily assessments could be collected. Thus, during 2 weeks, participants were repeatedly asked to complete the daily survey at 11 a.m. until they had responded five times. If they did not respond by 3 p.m., they received a reminder via e-mail. After their fifth and last entry, they were informed that they would receive feedback about their individual scores of the studied variables. We took precautions to protect confidentiality of the data and to prevent data manipulation (cf. Kraut et al., 2004) by using a password-protected server and by storing identifying information (e.g., e-mail addresses) in a different file than the study variables. Furthermore, participants received e-mail addresses and phone numbers by which they could request additional information on the study and communicate with the researchers.

\section{Measures}

\section{Chronic Level}

Self-esteem level. Participants completed the Rosenberg Self-Esteem Scale (Rosenberg, 1965; German version by 
TABLE 1: Means, Standard Deviations, and Correlations of Study Variables

\begin{tabular}{|c|c|c|c|c|c|c|c|c|c|}
\hline \multirow[b]{2}{*}{ Variable } & \multirow[b]{2}{*}{ M } & \multirow{2}{*}{$\begin{array}{l}\text { Between- } \\
\text { Person SD }\end{array}$} & \multirow{2}{*}{$\begin{array}{c}\text { Within- } \\
\text { Person SD }\end{array}$} & \multicolumn{6}{|c|}{ Correlation } \\
\hline & & & & 1 & 2 & 3 & 4 & 5 & 6 \\
\hline \multicolumn{10}{|l|}{ Chronic measures } \\
\hline 1. Depressive mood & 1.80 & 0.78 & - & - & -.15 & -.08 & $-.24 * *$ & .16 & $-.38 * *$ \\
\hline 2. Sex ${ }^{a}$ & 0.60 & - & - & & - & .15 & -.03 & .08 & .09 \\
\hline 3. Age & 41.93 & 11.44 & - & & & - & .08 & $-.24 * *$ & $-.19 *$ \\
\hline 4. Self-esteem level & 4.14 & 0.48 & - & & & & - & -.15 & .07 \\
\hline 5. Self-esteem instability & 0.41 & 0.28 & - & & & & & - & .03 \\
\hline 6. Interactional fairness & 4.98 & 1.13 & - & & & & & & - \\
\hline \multicolumn{10}{|l|}{ Daily measures } \\
\hline Depressive mood & 1.75 & 0.68 & 0.61 & & & & & & \\
\hline Unfair treatment & 0.35 & - & - & & & & & & \\
\hline
\end{tabular}

NOTE: $N=101$. For the daily measures: 150 diary measures (Level 1) of 30 individuals (Level 2). a. 0 = female, 1 = male.

$* p<.10 . * p<.05$.

von Collani \& Herzberg, 2003). They were instructed to complete 10 items according to how they felt about themselves in general. An item example is "I take a positive attitude toward myself." The format was a 5 -point Likert scale ( 1 = strongly disagree, 5 = strongly agree). Internal consistency was $\alpha=.82$.

Self-esteem instability. For each participant, selfesteem instability was computed as the standard deviation of five state self-esteem scores, a procedure introduced by Kernis (cf. Kernis \& Goldman, 2006). We assessd participants' state self-esteem by asking them to complete a short version (5 items; 7-point Likert-type scale, $1=$ strongly disagree, 7 = strongly agree) of the Rosenberg Self-Esteem Scale once a day during 5 working days (see above for details about the procedure). We reworded the instruction and the items to refer to how participants felt at that moment. The scale consisted of the following items: "I take a positive attitude toward myself"; "I am satisfied with myself"; "I feel that I am person of worth"; "I feel that I have good qualities"; "I have respect for myself." We calculated the reliability of the scale according to Nezlek (2007; Nezlek \& Gable, 2001); its value was good (.86). In this study, the correlation between self-esteem level and instability was $r=-.15$ (see Table 1), which corresponds to correlations reported in previous research (cf. Kernis \& Waschull, 1995).

Interactional fairness. We assessed interactional fairness with a scale by Niehoff and Moorman (1993). It consisted of nine items with a 7-point response format ( 1 = strongly disagree, 7 = strongly agree $)$. An item example is "When decisions are made about my job, my supervisor treats me with kindness and consideration." Internal consistency was $\alpha=.96$.

Depressive mood. Work-related depressive mood was measured with a scale by Warr (1990). Participants indicated how they had felt at work during the previous 2 weeks. The scale consisted of three items (depressed, miserable, gloomy) with a 5-point answering format $(1=$ not at all, $5=$ very much $)$. Internal consistency was $\alpha=.86$.

\section{Daily Level}

Unfair treatment at work. To assess type and frequency of negative events in the workplace, we used a shortened and adapted version of the Negative Event Scale (Maybery \& Graham, 2001). Of interest for this analysis was the occurrence of perceived unfair behavior (single item "Earlier this morning, ... . I felt treated unfairly"). The format was an ordinal scale $(0=$ no; $1=$ once; 2 =twice; 3 = three times or more). For subsequent analyses, the item was dichotomized to no (0) or yes (1) because the distribution of the responses was highly positively skewed.

Depressive mood. For the assessment of daily mood, we adapted the scale by Warr (1990). Participants indicated how they felt at that moment. As for the chronic level, the scale consisted of three items (depressed, miserable, gloomy) that were assessed on a 5 -point scale $(1=$ not at all, $5=$ very much $)$. The scale reliability was calculated according to Nezlek (2007; Nezlek \& Gable, 2001) and was good (.76).

\section{RESULTS}

\section{Overview of Analyses}

Our hypothesis was that low interactional fairness has a negative impact on people's mood, especially if their self-esteem is high and unstable. We tested this hypothesis with regard to fairness and depressive mood 
in general (chronic) and with regard to the occurrence of specific unfair events and daily mood.

Previous work has shown that sex and age are associated with self-esteem (e.g., Robins, Trzesniewski, Tracy, Gosling, \& Potter, 2002). Therefore, we controlled for sex and age. Furthermore, we controlled for several variables that could be related to the perception of unfair treatment, namely level of employment (expressed as percentage of a full-time equivalent), organizational tenure, and function as a supervisor $(0=n o, 1=y e s)$. However, controlling for these three control variables did not change the results; therefore, we did not include them in the final analyses.

\section{Chronic Measures}

To test our hypothesis with regard to chronic measures, we conducted hierarchical regression analyses. The predictor variables were centered on their grand mean to facilitate the interpretation of main effects in models containing interaction terms (see Aiken \& West, 1991). We entered the predictors into the regression in six steps: (a) sex and age; (b) self-esteem level and selfesteem instability; (c) the interaction of self-esteem level and self-esteem instability; (d) interactional fairness; (e) the two-way interactions of interactional fairness and self-esteem level, and interactional fairness and selfesteem instability; and finally (f) the three-way interaction of interactional fairness, self-esteem level, and selfesteem instability.

\section{Daily Measures}

The daily data are nested within persons, which leads to a number of statistical problems. The multilevel approach is ideally suited for this kind of data (Nezlek, 2001). Therefore, we analyzed the data with a multilevel random coefficient model using the program HLM 6.06 (Raudenbush, Bryk, Cheong, \& Congdon, 2004). We examined the within-person relationship between mood at work and the occurrence of perceived unfair treatment. This Level 1 predictor was dichotomous $(0=$ no unfair treatment occurred; 1 = unfair treatment occurred) and was not centered. Therefore, the Level 1 intercept represents the average depressive mood when no unfair treatment occurred. Of special interest was whether personal characteristics (i.e., self-esteem level and instability; both Level 2 variables) had an influence on the relationship between daily unfair treatment and mood (both Level 1 variables). The two Level 2 predictors were centered on the grand mean and entered together with their interaction term (i.e., Self-Esteem Level $\times$ Self-Esteem Stability) to predict (a) the Level 1 intercept (i.e., the influence of self-esteem level, selfesteem instability, and their interaction on mood) and (b) the Level 1 slope of unfair treatment (i.e., the influence of self-esteem level, self-esteem instability, and their interaction on the effect of unfair treatment on mood; representing cross-level interactions). Furthermore, sex and age were entered as covariates predicting the intercept and the slope. Thus, the Level 1 and Level 2 equations were as follows:

(Level 1)

Depressive $\operatorname{mood}_{\mathrm{ij}}=\beta_{0 \mathrm{j}}+\beta_{1 \mathrm{j}}$ (unfair treatment $)+\mathrm{r}_{\mathrm{ij}}$ (Level 2)

$$
\begin{gathered}
\left.\beta_{0 \mathrm{j}}=\gamma_{00}+\gamma_{01}(\text { sex })+\gamma_{02} \text { (age }\right)+\gamma_{03}(\text { self-esteem level })+ \\
\gamma_{04}(\text { self-esteem instability })+\gamma_{05}(\text { self-esteem level } \times \\
\text { self-esteem instability })+\mathrm{u}_{0 \mathrm{j}} \\
\beta_{1 \mathrm{j}}=\gamma_{10}+\gamma_{11}(\text { sex })+\gamma_{12}(\text { age })+\gamma_{13}(\text { self-esteem level })+ \\
\gamma_{14}(\text { self-esteem instability })+\gamma_{15}(\text { self-esteem level } \times \\
\text { self-esteem instability })+\mathrm{u}_{1 \mathrm{j}} .
\end{gathered}
$$

Several conditions had to be fulfilled to confirm our hypothesis: The coefficient $\gamma_{15}$ had to be significant and the pattern of the simple slopes had to be as predicted (i.e., strong relationship for people with unstable high self-esteem, no or only a moderate relationship for those with stable high self-esteem, and a moderate relationship for those with low self-esteem).

\section{Results of the Chronic Measures: Interactional Fairness and Mood}

Means, standard deviations, and zero-order correlations of all variables are shown in Table 1. Interactional fairness and self-esteem were negatively correlated with depressive mood. Table 2 displays the results of the regression analyses. In the following, we focus on the three-way interaction, which is central to our study.

The three-way interaction of interactional fairness, self-esteem level, and self-esteem instability was significant $(\beta=-.33, t=-2.48, p=.015)$, explaining an additional $5 \%$ of the variance. For a more specific test of our hypothesis, we conducted simple slope analyses as recommended by Aiken and West (1991). We also calculated slope difference tests following Dawson and Richter (2006). Interactional fairness was significantly related to depressive mood among people with unstable high self-esteem $(B=-.57, t=-4.22, p<.001)$ but not among people with stable high self-esteem $(B=-.13, t=$ $-1.26, p=.211)$. In addition, these two slopes differed significantly from each other $(t=-2.49, p=.015)$. Among individuals with low self-esteem, interactional fairness was marginally related to depressive mood 
TABLE 2: Summary of Hierarchical Regression Analysis for Variables Predicting Depressive Mood

\begin{tabular}{|c|c|c|c|c|c|}
\hline & Final B & Final SE B & $\beta$ In & Final $\beta$ & $\Delta \mathrm{R}^{2}$ \\
\hline Step 1 & & & & & .03 \\
\hline Sex ${ }^{a}$ & -0.24 & 0.14 & -.16 & $-.15 *$ & \\
\hline Age & 0.01 & 0.01 & .11 & .07 & \\
\hline Step 2 & & & & & $.10 * *$ \\
\hline SE level & -0.24 & 0.14 & $-.23 * *$ & -.15 & \\
\hline SE instability & 0.54 & 0.26 & $.19 *$ & $.19 * *$ & \\
\hline Step 3 & & & & & .01 \\
\hline SE Level $\times$ SE Instability & 0.62 & 0.69 & -.12 & .11 & \\
\hline Step 4 & & & & & $.12 * *$ \\
\hline Interactional fairness & -0.24 & 0.07 & $-.35 * *$ & $-.34 * *$ & \\
\hline Step 5 & & & & & .02 \\
\hline SE Level $\times$ Interactional Fairness & -0.22 & 0.15 & -.13 & -.16 & \\
\hline SE Instability $\times$ Interactional Fairness & -0.01 & 0.24 & -.10 & -.01 & \\
\hline Step 6 & & & & & $.05 *$ \\
\hline SE Level $\times$ SE Instability $\times$ Interactional Fairness & -1.64 & 0.66 & $-.33 * *$ & $-.33 * *$ & \\
\hline
\end{tabular}

NOTE: $N=101 . \mathrm{SE}=$ self-esteem. $\beta$ In $=$ Standardized coefficient when the variable was initially entered into the equation. Final $S E B / B /$ $\beta=$ coefficients at Step 6 .

a. 0 = female, 1 = male.

$* p<.10 . * p<.05$.

when self-esteem was stable $(B=-.34, t=-1.89, p=$ $.062)$, but not when it was unstable $(B=.10, t=0.58$, $p=.561)$. These two slopes differed from each other only marginally $(t=1.68, p=.096)$.

To summarize, the pattern for individuals with high self-esteem was as hypothesized (see Figure 1). Interactional fairness was related to depressive mood among people with unstable high self-esteem. In contrast, interactional fairness was not related to depressive mood among people with stable high self-esteem. However, an unexpected pattern emerged among individuals with low self-esteem. Interactional fairness was marginally related with depressive mood among people with stable low self-esteem but unrelated among those with unstable low self-esteem.

\section{Results of the Daily Measures: Unfair Treatment and Daily Mood}

Low interactional fairness in the workplace had an influence on mood on a chronic level, especially among people with unstable high self-esteem. In a next step we tested the central three-way interaction using the daily measures of perceived unfairness and depressive mood. Examination of the data showed that only a minority of the participants $(n=30)$ experienced at least one unfair treatment during the 5 working days on which the variables were assessed. Therefore, the following analysis is based on this subsample of participants. ${ }^{1}$ Furthermore, the outcome variable was highly skewed, with low values being most frequent and high values occurring only rarely (i.e., Poisson distribution). We, therefore, conducted a Poisson hierarchical linear modeling regression analysis.
However, the results were very similar to the results of a conventional hierarchical linear modeling regression analysis that is based on the assumption of a normally distributed outcome variable. Because conventional coefficients and slope tests are easier to interpret than coefficients resulting from Poisson regression analysis, we decided to present the results of the normal multilevel regression analysis. Results of the Poisson analysis can be obtained from the first author.

Before testing the hypothesis, we estimated the proportion of variance in the dependent variable accounted for by the situation (Level 1) and by the person (Level 2). We calculated a null model, which partitions the total variance of the dependent variable into within- and between-individual parts. The variance estimates were 0.44 for Level 2 and 0.47 for Level 1 . Thus, $52 \%(.47 /(.44+.47))$ of the total variance in depressive mood was explained within the person, which is substantial enough to be explained by potential situational variables (e.g., unfair treatment).

As reported in Table 3, overall, unfair treatment was not related to depressive $\operatorname{mood}\left(\gamma_{10}=.19, t=1.08, p=\right.$ $.282)$. However, the hypothesized interaction of SelfEsteem Level $\times$ Self-Esteem Instability had a significant impact on the slope $\left(\gamma_{15}=1.53, t=2.20, p=.029\right)$. Simple slope tests according to Preacher, Curran, and Bauer (2006) showed that unfair treatment was strongly related to daily depressive mood among people with unstable high self-esteem $(\gamma=.81, t=2.91, p=.004)$ but not among people with stable high self-esteem $(\gamma=.06$, $t=0.19, p=.848)$. Among individuals with low selfesteem, unfair treatment was not related to depressive mood, neither among those with unstable self-esteem 

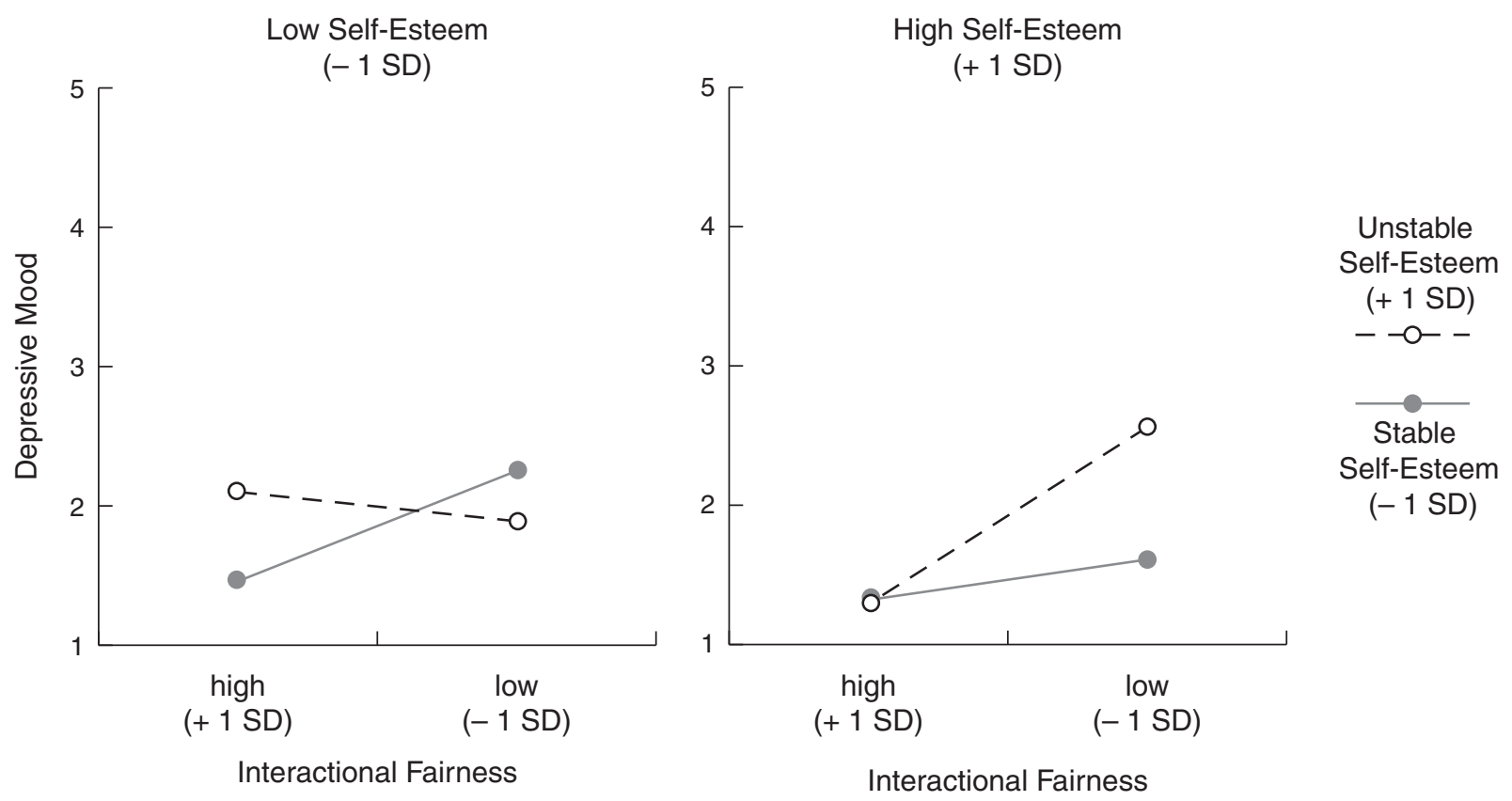

Figure 1 Interactions between interactional fairness and self-esteem instability predicting depressive mood for individuals with low and high self-esteem.

TABLE 3: Prediction of Daily Depressive Mood in Multilevel Analysis

\begin{tabular}{lll}
\hline & B & SE B \\
\hline Intercept $\left(\beta_{0}\right)$ & $1.57 * *$ & 0.16 \\
Unfair treatment $\left(\beta_{1}\right)$ & 0.19 & 0.17 \\
Effects on intercept $\left(\beta_{0}\right)$ & & \\
$\quad$ Sex $\left(\gamma_{01}\right)$ & 0.02 & 0.22 \\
Age $\left(\gamma_{02}\right)$ & 0.01 & 0.01 \\
SE level $\left(\gamma_{03}\right)$ & -0.07 & 0.22 \\
SE instability $\left(\gamma_{04}\right)$ & 0.29 & 0.28 \\
SE Level $\times$ SE Instability $\left(\gamma_{05}\right)$ & -0.38 & 0.31 \\
Effects on slope $\left(\beta_{1}\right)$ & & \\
Sex $\left(\gamma_{11}\right)$ & $0.42 *$ & 0.23 \\
Age $\left(\gamma_{12}\right)$ & $0.02 * *$ & 0.01 \\
SE level $\left(\gamma_{13}\right)$ & $0.48 * *$ & 0.20 \\
SE instability $\left(\gamma_{14}\right)$ & 0.30 & 0.30 \\
SE Level $\times$ SE Instability $\left(\gamma_{15}\right)$ & $1.53 * *$ & 0.28 \\
\hline
\end{tabular}

NOTE: The analyses are based on 150 data points (Level 1) for 30 individuals (Level 2). SE = self-esteem.

a. 0 = female, 1 = male.

$* p<.10 . * *<.05$.

$(\gamma=-.23, t=-0.90, p=.372)$ nor among those with stable self-esteem $(\gamma=.11, t=0.33, p=.742)$.

To summarize, for individuals with high self-esteem the pattern of results was as hypothesized (see Figure 2). Unfair treatment was related to depressive mood for people with unstable high self-esteem but not for people with stable high self-esteem. Again, an unexpected pattern emerged for individuals with low self-esteem. Unfair treatment was neither related to mood for people with unstable low self-esteem nor for those with stable low self-esteem. Overall, the results of the diary measures are similar to those of the chronic measures of fairness and mood.

\section{DISCUSSION}

The goal of this study was to test how self-esteem level and self-esteem instability moderate the impact of perceived unfair behavior on depressive mood. According to the sociometer theory (Leary et al., 1995), people with low self-esteem are expected to react more strongly to unfairness than are those with high self-esteem because they are more sensitive to interpersonal rejection. However, not all individuals with high self-esteem are confident about their worth and social standing. In contrast to people with stable high self-esteem, people with unstable high self-esteem are particularly reactive to negative feedback and social exclusion. Therefore, we proposed that individuals with unstable high selfesteem would also react strongly to unfair treatment.

Whereas previous research focused solely on the moderating role of either self-esteem level or instability (De Cremer et al., 2004; De Cremer \& Sedikides, 2005), we focused on the interaction of self-esteem level and 


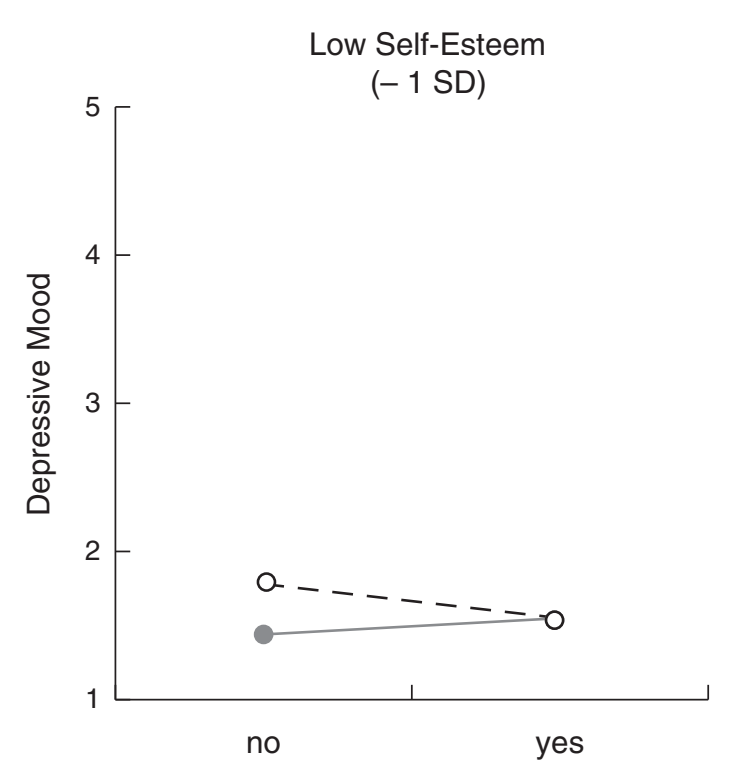

Unfair Treatment

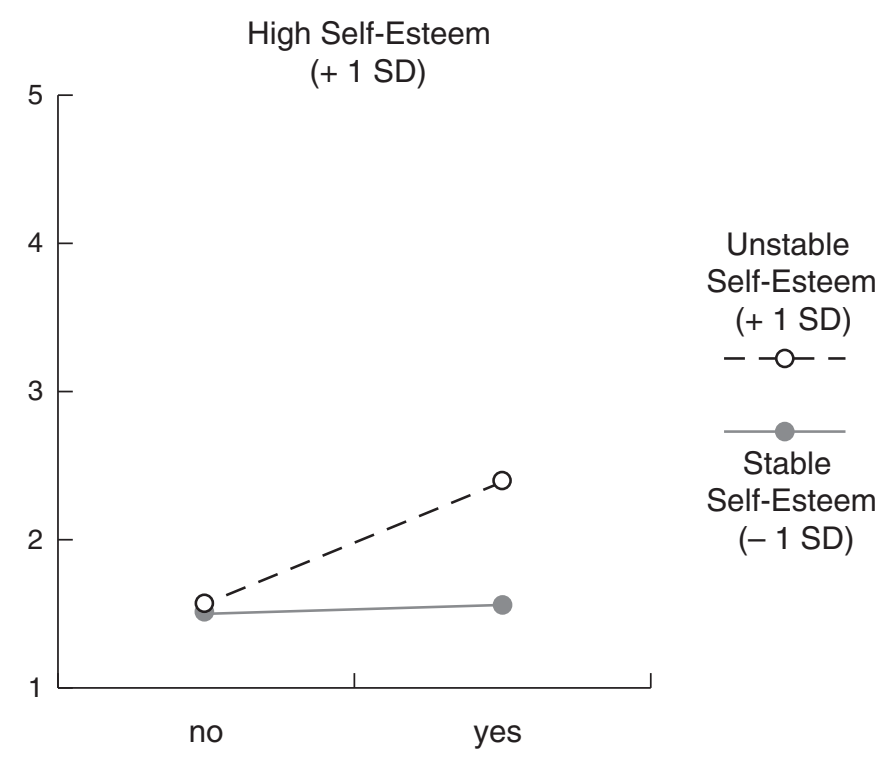

Unfair Treatment

Figure 2 Interactions between unfair treatment and self-esteem instability predicting daily depressive mood for individuals with low and high self-esteem.

instability. In line with our hypothesis, people with unstable high self-esteem reacted strongly to unfair treatment, as indicated by a measure of depressive mood. Interactional fairness was only related to chronic depressive mood among people with unstable high selfesteem but not among individuals with stable high selfesteem. The same pattern was found in the diary study. This finding is in line with previous research showing that people with stable high self-esteem have secure positive self-feelings that will not easily be threatened by adverse events. In contrast, people with unstable high self-esteem are highly vulnerable to social threats (cf. Kernis, 2005).

The role of self-esteem instability in the development of depressive mood or depression has been repeatedly tested, and the evidence suggests that unstable selfesteem might be an important vulnerability marker for depression (e.g., Franck \& De Raedt, 2007; Hayes, Harris, \& Carver, 2004; Kernis et al., 1998; Roberts, Kassel, \& Gotlib, 1995; Roberts \& Monroe, 1992). In most previous research, instability has been related to depressive symptoms among individuals with high and low self-esteem. In contrast, our results suggest that the relationship between stressful events (i.e., unfair treatment) and depressive mood is more pronounced for people with unstable high self-esteem as compared to unstable low self-esteem.
A somewhat unexpected finding emerged among individuals with low self-esteem. Chronic unfair treatment was marginally related to depressive mood among people with stable low self-esteem but unrelated among those with unstable low self-esteem. On a daily level, unfair treatment was unrelated to depressive mood for both stable and unstable low self-esteem. It has to be noted, however, that inconsistent findings have emerged in the past for individuals with low selfesteem as a function of self-esteem instability (e.g., Kernis, Cornell, Sun, Berry, \& Harlow, 1993; Kernis, Grannemann, \& Mathis, 1991; Paradise \& Kernis, 2002; for a summary, see Kernis \& Waschull, 1995). Furthermore, these results show similarities with recent findings by Wiesenfeld, Swann, Brockner, and Bartel (2007), indicating that procedural fairness was not related to commitment and absenteeism among people with low self-esteem.

One possible explanation for the inconsistent results may lie in the measurement of self-esteem. In this study, we assessed self-esteem with the most widely used measure, the Rosenberg Self-Esteem Scale (Rosenberg, 1965; cf. Blascovich \& Tomaka, 1991), which operationalizes self-esteem as a global, affective evaluation of the self. We chose this measure because most studies on self-esteem instability are based on this scale and our findings should be comparable with previous research. 
However, some authors suggested that investigators who focus on the socially constructed self should address the social dimension of self-esteem instead of global self-esteem (e.g., De Cremer, 2003). It is interesting to note that studies using social self-esteem as a moderator variable confirmed the assumption that low (social) self-esteem people react strongly to unfairness. Thus, it is possible that our findings would be more in line with our assumptions-which are based on the group-value model as well as on the sociometer theory, both focusing on the social self-if we had used a selfesteem measure that assesses the social aspect of selfesteem (i.e., being socially accepted and attractive in relationships). Future studies should examine the impact of different measures of self-esteem on the moderating effects of self-esteem in fairness research.

\section{Strengths, Limitations, Future Research, and Conclusion}

The study reported here has several strengths. For the first time, self-esteem level and self-esteem instability were simultaneously linked to the effect of unfair treatment. Previous research focused solely on the level (De Cremer et al., 2004) or the stability (De Cremer \& Sedikides, 2005) of self-esteem. As these findings suggest, however, the impact of self-esteem instability depends on the level of self-esteem. Furthermore, the moderating role of self-esteem in the relationship between organizational fairness and well-being has only rarely been tested in field studies. We believe that a realworld context is crucial for testing propositions of the relation model of fairness (Tyler \& Lind, 1992). The need to be respected and valued by one's supervisor should be stronger in a setting where people meet their supervisor on a daily basis than in an experimental situation in the lab. Therefore, field studies are a necessary complement to experimental studies, with pros and cons for both methods. Another strength of our study is that we tested our hypothesis with two different time perspectives, a cross-sectional study design and a diary study design. Both studies showed similar results, indicating that the impact of unfair treatment was similar in the short term and the longer term, and that the effect of individual differences can be replicated. Diary studies are an interesting method to examine the impact of events in daily life (see Bolger, Davis, \& Rafaeli, 2003; Nezlek, 2001). Only few, however, tested the effect of unfairness using a within-person analysis (for an exception, see Judge, Scott, \& Ilies, 2006), and we hope that this study will inspire future research.

Several limitations also have to be acknowledged. First, the major shortcoming is the reduced sample size in the diary study. Although the results mirror the findings for the chronic measures, they should be interpreted with caution and should be replicated. In this study, only a minority of employees reported an unfair event during the working days on which the diary data were collected. If possible, future studies should collect data for larger samples and longer time periods. Second, because of restrictions in questionnaire length (the study was conducted during work time), we had to use a single-item measure for unfair treatment in the diary study. Third, this item was unspecific with regard to the type of unfairness (i.e., distributive, procedural, or interactional unfairness). However, all three types of unfairness have been linked to respect and threat to self-esteem (distributive unfairness, see De Cremer, 2002b; procedural fairness, see Koper, van Knippenberg, Bouhuijs, Vermunt, \& Wilke, 1993; interactional fairness, see De Cremer et al., 2004) and some authors have underlined the benefits of a more general view on fairness topics (e.g., Ambrose \& Arnaud, 2005; Semmer, Jacobshagen, Meier, \& Elfering, 2007). Nevertheless, multi-item measures of the different fairness dimensions should be used in future research.

Fourth, in line with the majority of research on fairness (see Folger \& Cropanzano, 1998), we focused solely on negative mood as outcome. However, recent evidence indicates that fairness also influences people's positive affect (e.g., De Cremer, 2004; De Cremer \& Alberts, 2004; De Cremer \& Sedikides, 2005, Experiment 2; Krehbiel \& Cropanzano, 2000; van den Bos \& Spruijt, 2002) and behavior (De Cremer et al., 2004; Wiesenfeld et al., 2007). It is interesting that previous studies that found moderating effects of self-esteem level (De Cremer et al., 2004) and instability (De Cremer \& Sedikides, 2005) focused on positive affect and behavior. Given that positive and negative mood are conceptualized as two distinct dimensions (e.g., Watson, Clark, \& Tellegen, 1988; Diener, Larsen, Levine, \& Emmons, 1985 ) and that negative events influence negative affect more strongly than positive affect (e.g., Gable, Reis, \& Elliot, 2000), future studies should examine both positive and negative affect as outcome variables. Fifth, the design of this study does not allow for causal inferences because the variables were measured concurrently, even in the diary study design. In future studies using diary data, unfair treatment and wellbeing should be measured at clearly separate points in time (e.g., unfair treatment during work-time and wellbeing before going to bed), which would allow for stronger conclusions regarding possible causal influences of unfair treatment on well-being. Sixth, although we postulate that unfair treatment is a threat to social exclusion and self-esteem, we did not directly test this notion in this study. Future research may want to include social exclusion as a mediating variable. 
In sum, our findings suggest that perceived unfair treatment by supervisors is related to impaired wellbeing and that people with an unstable high self-esteem are especially vulnerable to unfairness. It seems that people with a high but unstable self-esteem possess a valuable quality (i.e., high self-esteem), which, however, is in constant danger (as indicated by low stability). It is plausible that they are especially vigilant to signals of threat to their valued quality and their reactions are especially strong to these threats. Thus, our results confirm current theorizing and empirical evidence with regard to the role of high but unstable self-esteem, and they do so with data obtained in a field setting and referring to both chronic conditions and daily events. At the same time, an unexpected pattern emerged for people with low self-esteem. Thus, our results imply that more work is needed to gain a better understanding of the processes that are involved in the reactions to unfair treatment by people with low self-esteem.

\section{NOTE}

1. The results were very similar when we conducted an analysis with the complete sample $(N=101)$. Of particular importance, the three-way interaction was also significant.

\section{REFERENCES}

Aiken, L. S., \& West, S. G. (1991). Multiple regression: Testing and interpreting interactions. Newbury Park, CA: Sage.

Ambrose, M. L., \& Arnaud, A. (2005). Are procedural justice and distributive justice conceptually distinct? In J. Greenberg \& J. A. Colquitt (Eds.), Handbook of organizational justice (pp. 59-84). Mahwah, NJ: Lawrence Erlbaum.

Baumeister, R. F., \& Leary, M. R. (1995). The need to belong: Desire for interpersonal attachments as a fundamental human motivation. Psychological Bulletin, 117, 497-529.

Blascovich, J., \& Tomaka, J. (1991). Measures of self-esteem. In J. P. Robinson, P. R. Shaver, \& L. R. Wrightsman (Eds.), Measures of personality and social psychological attitudes (pp. 115-160). New York: Academic Press.

Bolger, N., Davis, A., \& Rafaeli, E. (2003). Diary methods: Capturing life as it is lived. Annual Review of Psychology, 54, 579-616.

Bolger, N., DeLongis, A., Kessler, R. C., \& Schilling, E. A. (1989). Effects of daily stress on negative mood. Journal of Personality and Social Psychology, 57, 808-818.

Brockner, J., Heuer, L., Siegel, P. A., Wiesenfeld, B., Martin, C., Grover, S., et al. (1998). The moderating effect of self-esteem in reaction to voice: Converging evidence from five studies. Journal of Personality and Social Psychology, 75, 394-407.

Cohen-Charash, Y., \& Byrne, Z. S. (in press). Affect and justiceCurrent knowledge and future directions. In N. M. Ashkanasy \& C. L. Cooper (Eds.), Research companion to emotion in organizations. Cheltenham, UK: Edward Elgar.

Colquitt, J. A., Greenberg, J., \& Zapata-Phelan, C. P. (2005). What is organizational justice? A historical overview. In J. Greenberg \& J. A. Colquitt (Eds.), Handbook of organizational justice (pp. 3-56). Mahwah, NJ: Lawrence Erlbaum.

Corning, A. F. (2002). Self-esteem as a moderator between perceived discrimination and psychological distress among women. Journal of Counseling Psychology, 49, 117-126.
Dawson, J. F., \& Richter, A. W. (2006). Probing three-way interactions in moderated multiple regression: Development and application of a slope difference test. Journal of Applied Psychology, 91, 917-926.

De Cremer, D. (2002a). Exploring the instrumental versus non-instrumental aspects of procedural fairness: The usefulness of a person $x$ situation approach. In F. Columbus (Ed.), Advances in psychology research (Vol. 15, pp. 157-172). New York: NOVA.

De Cremer, D. (2002b). The self-relevant implications of distribution rules: When self-esteem and acceptance are influenced by violations of the equity rule. Social Justice Research, 15, 327-339.

De Cremer, D. (2003). Why inconsistent leadership is regarded as procedurally unfair: The importance of social self-esteem concerns. European Journal of Social Psychology, 33, 535-550.

De Cremer, D. (2004). The influence of accuracy as a function of leader's bias: The role of trustworthiness in the psychology of procedural justice. Personality and Social Psychology Bulletin, 30, 293-304.

De Cremer, D., \& Alberts, H. J. E. M. (2004). When procedural fairness does not influence how positive I feel: The effects of voice and leader selection as a function of belongingness need. European Journal of Social Psychology, 34, 333-344.

De Cremer, D., \& Sedikides, C. (2005). Self-uncertainty and responsiveness to procedural justice. Journal of Experimental Social Psychology, 41, 157-173.

De Cremer, D., van Knippenberg, D., van Dijke, M., \& Bos, A. E. R. (2004). How self-relevant is fair treatment? Social self-esteem moderates interactional justice effects. Social Justice Research, 17, 407-419.

Diener, E., Larsen, R. J., Levine, S., \& Emmons, R. A. (1985). Intensity and frequency: Dimensions underlying positive and negative affect. Journal of Personality and Social Psychology, 48, 1253-1265.

Fischer, A. R., \& Bolton Holz, K. (2007). Perceived discrimination and women's psychological distress: The roles of collective and personal self-esteem. Journal of Counseling Psychology, 54, 154-164.

Fischer, A. R., \& Shaw, C. M. (1999). African Americans' mental health and perceptions of racist discrimination: The moderating effects of racial socialization experiences and self-esteem. Journal of Counseling Psychology, 46, 395-407.

Folger, R., \& Cropanzano, R. (1998). Organizational justice and human resource management. Thousand Oaks, CA: Sage

Franck, E., \& De Raedt, R. (2007). Self-esteem reconsidered: Unstable self-esteem outperforms level of self-esteem as vulnerability marker for depression. Behaviour Research and Therapy, 45, 1531-1541.

Gable, S. L., Reis, H. T., \& Elliot, A. J. (2000). Behavioral activation and inhibition in every-day life. Journal of Personality and Social Psychology, 78, 1135-1149.

Greenier, K. D., Kernis, M. H., McNamara, C. W., Waschull, S. B., Berry, A. J., Herlocker, C. E., et al. (1999). Individual differences in reactivity to daily events: Examining the roles of stability and level of self-esteem. Journal of Personality, 67(1), 185-208.

Hayes, A. M., Harris, M. S., \& Carver, C. S. (2004). Predictors of self-esteem variability. Cognitive Therapy and Research, 28, 369-385.

Heatherton, T. F., \& Polivy, J. (1991). Development and validation of a scale for measuring state self-esteem. Journal of Personality and Social Psychology, 60, 895-910.

Judge, T. A., Erez, A., Bono, J. E., \& Thoresen, C. J. (2002). Are measures of self-esteem, neuroticism, locus of control, and generalized self-efficacy indicators of a common core construct? Journal of Personality and Social Psychology, 83, 693-710.

Judge, T. A., Scott, B. A., \& Ilies, R. (2006). Hostility, job attitudes, and workplace deviance: Test of a multilevel model. Journal of Applied Psychology, 91, 126-138.

Kernis, M. H. (2005). Measuring self-esteem in context: The importance of stability of self-esteem in psychological functioning. Journal of Personality, 73(6), 1-37.

Kernis, M. H., Cornell, D. P., Sun, C. R., Berry, A., \& Harlow, T. (1993). There's more to self-esteem than whether it is high or low-The importance of stability of self-esteem. Journal of Personality and Social Psychology, 65, 1190-1204. 
Kernis, M. H., \& Goldman, B. M. (2006). Assessing stability of selfesteem and contingent self-esteem. In M. H. Kernis (Ed.), Self esteem issues and answers: A sourcebook of current perspectives (pp. 77-85). New York: Psychology Press.

Kernis, M. H., Grannemann, B. D., \& Barclay, L. C. (1989). Stability and level of self-esteem as predictors of anger arousal and hostility. Journal of Personality and Social Psychology, 56, 1013-1022.

Kernis, M. H., Grannemann, B. D., \& Mathis, L. C. (1991). Stability of self-esteem as a moderator of the relation between level of selfesteem and depression. Journal of Personality and Social Psychology, 61, 80-84.

Kernis, M. H., Greenier, K. D., Herlocker, C. E., Whisenhunt, C. R., \& Abend, T. A. (1997). Self-perceptions of reactions to doing well or poorly: The roles of stability and level of self-esteem. Personality and Individual Differences, 22, 845-854.

Kernis, M. H., \& Waschull, S. B. (1995). The interactive roles of stability and level of self-esteem: Research and theory. In M. P. Zanna (Ed.), Advances in experimental social psychology (Vol. 27, pp. 93-141). San Diego, CA: Academic Press.

Kernis, M. H., Whisenhunt, C. R., Waschull, S. B., Greenier, K. D., Berry, A. J., Herlocker, C. E., et al. (1998). Multiple facets of selfesteem and their relations to depressive symptoms. Personality and Social Psychology Bulletin, 24, 657-668.

Koper, G., van Knippenberg, D., Bouhuijs, F., Vermunt, R., \& Wilke, H. (1993). Procedural fairness and self-esteem. European Journal of Social Psychology, 23, 313-325.

Kraut, R., Olson, J., Banaji, M., Bruckman, A., Cohen, J., \& Couper, M. (2004). Psychological research online: Report of Board of Scientific Affairs' Advisory Group on the Conduct of Research on the Internet. American Psychologist, 59(2), 105-117.

Krehbiel, P. J., \& Cropanzano, R. (2000). Procedural justice, outcome favorability and emotion. Social Justice Research, 13, 339-360.

Leary, M. R. (1990). Responses to social exclusion: Social anxiety, jealousy, loneliness, depression, and low self-esteem. Journal of Social and Clinical Psychology, 9, 221-229.

Leary, M. R. (Ed.). (2001). Interpersonal rejection. New York: Oxford University Press.

Leary, M. R. (2004). The sociometer, self-esteem, and the regulation of interpersonal behavior. In R. F. Baumeister \& K. Vohs (Eds.), Handbook of self-regulation (pp. 373-391). New York: Guilford.

Leary, M. R., Tambor, E. S., Terdal, S. K., \& Downs, D. L. (1995). Self-esteem as an interpersonal monitor: The sociometer hypothesis. Journal of Personality and Social Psychology, 68, 518-530.

Lind, E. A., \& Tyler, T. R. (1988). The social psychology of procedural justice. New York: Plenum.

Maybery, D. J., \& Graham, D. (2001). Hassles and uplifts: Including interpersonal events. Stress and Health: Journal of the International Society for the Investigation of Stress, 17(2), 91-104.

Mikula, G., Scherer, K. R., \& Athenstaedt, U. (1998). The role of injustice in the elicitation of differential emotional reactions. Personality and Social Psychology Bulletin, 24, 769-783.

Moradi, B., \& Subich, L. M. (2004). Examining the moderating role of self-esteem in the link between experiences of perceived sexist events and psychological distress. Journal of Counseling Psychology, $51,50-56$.

Nezlek, J. B. (2001). Multilevel random coefficient analyses of event- and interval-contingent data in social and personality psychology research. Personality and Social Psychology Bulletin, 27, 771-785.

Nezlek, J. B. (2007). Multilevel modeling in research on personality. In R. Robins, R. C. Fraley, \& R. Krueger (Eds.), Handbook of research methods in personality psychology (pp. 502-523). New York: Guilford.

Nezlek, J. B., \& Gable, S. L. (2001). Depression as a moderator of relationships between positive day events and day-to-day psychological adjustment. Personality and Social Psychology Bulletin, 27, 1692-1704.

Nezlek, J. B., Kowalski, R. M., Leary, M. R., Blevins, T., \& Holgate, S. (1997). Personality moderators of reactions to interpersonal rejection: Depression and trait self-esteem. Personality and Social Psychology Bulletin, 23, 1235-1244.
Nezlek, J. B., \& Plesko, R. M. (2001). Day-to-day relationships among self-concept clarity, self-esteem, daily events, and mood. Personality and Social Psychology Bulletin, 27, 201-211.

Nezlek, J. B., \& Plesko, R. M. (2003). Affect- and self-based models of relationships between daily events and daily well-being. Personality and Social Psychology Bulletin, 29, 584-596.

Niedhammer, I., David, S., \& Degioanni, S. (2006). Association between workplace bullying and depressive symptoms in the French working population. Journal of Psychosomatic Research, 61, 251-259.

Niehoff, B. P., \& Moorman, R. H. (1993). Justice as a mediator of the relationship between methods of monitoring and organizational citizenship behavior. Academy of Management Journal, 36, 527-556.

Nolan, S. A., Flynn, C., \& Garber, J. (2003). Prospective relations between rejection and depression in young adolescents. Journal of Personality and Social Psychology, 85, 745-755.

Paradise, A. W., \& Kernis, M. H. (2002). Self-esteem and psychological well-being: Implications of fragile self-esteem. Journal of Social and Clinical Psychology, 21, 345-361.

Preacher, K. J., Curran, P. J., \& Bauer, D. J. (2006). Computational tools for probing interaction effects in multiple linear regression, multilevel modeling, and latent curve analysis. Journal of Educational and Behavioral Statistics, 31, 437-448.

Raudenbush, S. W., Bryk, A. S., Cheong, Y. K., \& Congdon, R. T., Jr. (2004). HLM 6: Hierarchical linear and nonlinear modeling (Ver. 6.06). Lincolnwood, IL: Scientific Software International.

Roberts, J. E., Kassel, J. D., \& Gotlib, I. H. (1995). Level and stability of self-esteem as predictors of depressive symptoms. Personality and Individuals Differences, 19, 217-224.

Roberts, J. E., \& Monroe, S. M. (1992). Vulnerable self-esteem and depressive symptoms: Prospective findings comparing three alternative conceptualizations. Journal of Personality and Social Psychology, 62, 804-812.

Robins, R. W., Trzesniewski, K. H., Tracy, J. L., Gosling, S. D., \& Potter, J. (2002). Global self-esteem across the life span. Psychology and Aging, 17, 423-434.

Rosenberg, M. (1965). Society and the adolescent self-images. Princeton, NJ: Princeton University Press.

Schulz, A. J., Gravlee, C. C., Williams, D. R., Israel, B. A., Mentz, G., \& Rowe, Z. (2006). Discrimination, symptoms of depression, and self-rated health among African American women in Detroit: Results from a longitudinal analysis. American Journal of Public Health, 96, 1265-1270.

Semmer, N. K., Jacobshagen, N., Meier, L. L., \& Elfering, A. (2007). Occupational stress research: The "stress-as-offense-to-self" perspective. In S. McIntyre \& J. Houdmont (Eds.), Occupational health psychology: European perspectives on research, education, and practice (Vol. 2, pp. 41-58). Avioso S. Pedro, Portugal: Instituto Superior da Maia.

Sonnentag, S., \& Zijlstra, F. H. (2006). Job characteristics and off-job activities as predictors of need for recovery, well-being, and fatigue. Journal of Applied Psychology, 91, 330-350.

Stone-Romero, E. F., \& Stone, D. L. (2005). How do organizational justice concepts relate to discrimination and prejudice? In J. Greenberg \& J. A. Colquitt (Eds.), Handbook of organizational justice (pp. 439-467). Mahwah, NJ: Lawrence Erlbaum.

Thibaut, J., \& Walker, L. (1975). Procedural justice: A psychological analysis. Hillsdale, NJ: Lawrence Erlbaum.

Tyler, T. R., \& Lind, E. A. (1992). A relational model of authority in groups. In M. P. Zanna (Ed.), Advances in experimental social psychology (Vol. 25, pp. 115-191). San Diego, CA: Academic Press.

van den Bos, K., \& Spruijt, N. (2002). Appropriateness of decisions as a moderator of the psychology of voice. European Journal of Social Psychology, 32, 57-72.

von Collani, G., \& Herzberg, P. Y. (2003). Eine revidierte Fassung der deutschsprachigen Skala zum Selbstwertgefühl von Rosenberg [A revised version of the German adaptation of Rosenberg's SelfEsteem Scale]. Zeitschrift für Differentielle und Diagnostische Psychologie, 24(1), 3-7. 
Warr, P. B. (1990). The measurement of well-being and other aspects of mental health. Journal of Occupational Psychology, 63, 193-210.

Watson, D., Clark, L. A., \& Tellegen, A. (1988). Development and validation of brief measures of positive and negative affect: The PANAS scales. Journal of Personality and Social Psychology, 54, 1063-1070.

Weiss, H. M., Suckow, K., \& Cropanzano, R. (1999). Effects of justice conditions on discrete emotions. Journal of Applied Psychology, 84, 786-794.

Wiesenfeld, B. M., Swann, W. B., Brockner, J., \& Bartel, C. A. (2007). Is more fairness always preferred? Self-esteem moderates reactions to procedural justice. Academy of Management Journal, 50, 1235-1253.

Williams, K. P. (2007). Ostracism. Annual Review of Psychology, 58, 425-452.
Ylipaavalniemi, J., Kivimäki, M., Elovainio, M., Virtanen, M., Keltikangas-Järvinen, L., \& Vahtera, J. (2005). Psychosocial work characteristics and incidence of newly diagnosed depression: A prospective cohort study of three different models. Social Science and Medicine, 61(1), 111-122.

Zeigler-Hill, V., \& Showers, C. J. (2007). Self-structure and selfesteem stability: The hidden vulnerability of compartmentalization. Personality and Social Psychology Bulletin, 33, 143-159.

Received November 5, 2007

Revision accepted December 1, 2008 